\title{
Mobile Internet Use and Multidimensional Poverty: Evidence from A Household Survey in Rural China
}

\author{
Long Yang ${ }^{1} \cdot$ Haiyang $\mathrm{Lu}^{2}$ (I) $\cdot$ Sangui Wang ${ }^{3} \cdot{\mathrm{Meng} \mathrm{Li}^{4}}^{4}$
}

Accepted: 10 June 2021 / Published online: 14 June 2021

(c) The Author(s), under exclusive licence to Springer Nature B.V. 2021

\begin{abstract}
Although reducing poverty has become an important issue for rural development in China, few studies have analyzed the role of mobile Internet use in multidimensional poverty. To fill this gap, this study investigated the impact of mobile Internet use on multidimensional poverty, using data collected from a household survey in rural China. Because households generally decide whether to use mobile Internet by themselves, an endogenous switching regression model was employed to control for potential selection bias. In total, $9.63 \%$ of the households were identified as multidimensionally poor and the adjusted multidimensional poverty incidence was $5.47 \%$. The results also showed that mobile Internet use has a significant negative impact on multidimensional poverty. Further, we provide evidence of heterogeneity in the effect of mobile Internet use across regions. These findings highlight the importance of mobile Internet use in multidimensional poverty reduction strategies for rural households.
\end{abstract}

Keywords Mobile Internet use $\cdot$ Multidimensional poverty $\cdot$ Endogenous switching regression model $\cdot$ Heterogeneous effect

Haiyang Lu

luhy@swufe.edu.cn

Long Yang

long.yang@fafu.edu.cn

Sangui Wang

wangsg@ruc.edu.cn

Meng Li

meng.li@fafu.edu.cn

1 School of Public Management, Fujian Agriculture and Forestry University, Fuzhou 350002, People's Republic of China

2 The West Center for Economic Research, Southwestern University of Finance and Economics, Chengdu 611130, People's Republic of China

3 School of Agricultural Economics and Rural Development, Renmin University of China, Beijing 100872, People's Republic of China

4 Colleage of Economics and Management, Fujian Agriculture and Forestry University, Fuzhou 350002, People's Republic of China 


\section{Introduction}

Information and communication technologies (ICTs) are increasingly important in accelerating economic growth for developing countries. Particularly, ICTs such as mobile Internet and smartphones may reduce transaction costs, increase labor productivity, and improve innovation capacity (Lio \& Liu, 2006; Ma et al., 2018; Paunov \& Rollo, 2016). Thus, many developing countries implement supportive policies to boost ICT development. For example, China has issued a series of policies related to the "Internet plus" initiative (Xie et al., 2019), aiming to improve various fields such as education, health care, finance, and commerce. Given their importance, ICTs have recently received more attention from policymakers and researchers in developing and emerging economies.

A growing body of literature has examined the relationship between ICTs and economic growth at the macro level, mainly focusing on GDP growth, employment rate, and agricultural productivity (Atasoy, 2013; Lio \& Liu, 2006; Niebel, 2018; Qiang et al., 2009). Previous studies found that ICTs boosted economic development and increased economic performance. For example, Qiang et al. (2009) found that broadband penetration positively impacted GDP growth for both developing and developed countries. In the United States, Atasoy (2013) examined the nexus between ICTs and employment rate and found that broadband use increased the employment rate by 1.8 percent. Using data for 81 countries, Lio and Liu (2006) examined the association between adoption of ICTs and agricultural productivity and found that new ICTs significantly improved agricultural productivity. However, there are still debates about the impact of ICTs on inclusive development. For instance, compared to high-income economies, Qiang et al. (2009) showed that the economic impact of broadband was larger for low- and middle-income economies. Contrary to Qiang et al. (2009), using data for 59 countries, Niebel (2018) found that developing countries were not gaining more from investments in ICTs than developed economies.

Other publications have examined the effect of adopting ICTs on organization performance and labor productivity at the firm level. For example, using Chinese firm-level production data, Fernandes et al. (2019) found that access to the Internet increased overall firm performance due to improved communication with buyers and suppliers. In Italy, Colombo et al. (2013) examined the effect of ICTs on productivity of small and medium enterprises (SMEs) and found that adopting advanced ICTs had a positive effect on SMEs' productivity. With regard to labor productivity, some researchers found that access to the Internet improved firm labor productivity and expanded total employment, especially for micro and small firms (Paunov \& Rollo, 2016; Viollaz, 2019). This is because adopting ICTs results in the formalization of a labor relationship, which improves labor productivity. Furthermore, previous studies also identified the effect of adopting ICTs on different types of businesses. For the banking industry, ICTs had a positive impact on banking profitability and stability improvement, attributed to the intensive adoption of both IT and financial technologies (Del Gaudio et al., 2020). In their study on logistics firms, Lei et al. (2021) provided empirical evidence for the positive impact of different ICTs such as enterprise systems (ES) and Internet of Things (IoT) use on service diversification.

Given the importance of ICTs, several studies have attempted to analyze the relationship between adopting ICTs and reducing poverty. However, to date, the findings in previous studies are mixed (Beuermann et al., 2012; Fu \& Akter, 2016; Hübler \& Hartje, 2016; Langmia, 2005; Mbuyisa \& Leonard, 2017; Munyegera \& Matsumoto, 2018; Sujarwoto \& Tampubolon, 2016). Most of the studies hold the view that adopting ICTs has the potential to improve economic well-being and reduce poverty. For instance, using data from Peru, 
Beuermann et al. (2012) found that mobile phone use increased consumption and lowered poverty incidence. In particular, the study showed that access to mobile phones has a positive impact on extreme poverty because of the spillover effects of adopting ICTs. In India, Fu and Akter (2016) found that ICTs improved farmers' desire to adopt updated technology and increased agricultural knowledge, which resulted in poverty alleviation in the future. Furthermore, ICTs reduced transaction costs (e.g. transportation fares and service charges) and increased the likelihood of saving, borrowing, and receiving remittances, contributing to access to digital financial services (Munyegera \& Matsumoto, 2018). Using data from rural Southeast Asia, Hübler and Hartje (2016) confirmed the poverty reduction effects of ICTs and found that owning ICTs such as smartphones has a significant and positive effect on household annual income. Moreover, Mbuyisa and Leonard (2017) concluded that ICTs could be used by SMEs as a tool for reducing poverty. ICTs enhanced the abilities of business owners and improved business operations, thereby increasing income and reducing vulnerabilities.

However, some studies show that adopting ICTs has no significant effects on poverty reduction in developing countries. For example, Langmia (2005) argued that challenges existed in using ICTs for economic development in South Africa, especially in the rural areas, due to the lack of telecommunication and ancillary infrastructure (e.g. telephone lines and an electricity grid). These challenges may hinder the role of ICTs in reducing poverty. Moreover, the telecommunication infrastructure and Internet divide was widening and deepening across urban-rural and city-countryside areas, especially remote areas (Sujarwoto \& Tampubolon, 2016), stemming from the high cost and low profit of providing telecommunication service for rural areas compared to urban areas (Salemink et al., 2017). The Internet divide prevents rural households from having access to the benefits of ICT services (van Deursen \& van Dijk, 2019), resulting in income inequality and low effectiveness of poverty reduction. A few studies even found a negative association between adopting ICTs and household welfare. For instance, in a study on "Taobao villages" in China, Tang and Zhu (2020) found that the diffusion of ICTs negatively affected local industry and household welfare. This may be attributed to the influx of large numbers of migrants into "Taobao villages", which in turn leads to higher labor costs and distorted prices of products and production elements.

Although the existing literature has investigated the role of ICTs and examined the relationship between ICTs and poverty reduction, few studies have analyzed the nexus between mobile Internet use and multidimensional poverty. Among various types of ICTs, mobile Internet has spread widely in recent years with the availability of mobile devices such as smartphones and tablets. In contrast to broadband Internet, mobile Internet enables households to access current information regardless of location. In addition, it helps households use mobile financial services and mobile commerce, reducing transaction costs and improving production efficiency. It is also worth noting that recent studies have paid increasing attention to poverty reduction from the perspective of multidimensionality (e.g. income, health, and education) (Alkire \& Foster, 2011; Nowak \& Scheicher, 2017; Strotmann \& Volkert, 2018). We argue that knowledge of the relationship between mobile Internet use and multidimensional poverty would provide important insights for policymakers as to what sorts of interventions might be used in reducing multidimensional poverty. So far, however, the effect of mobile Internet use on multidimensional poverty remains understudied.

The objective of this study was to measure multidimensional poverty in rural China and investigate the impact of mobile Internet use on multidimensional poverty. We chose six dimensions, including income, health, assets, public service, overall satisfaction, and 
self-rated happiness in measuring multidimensional poverty. Using a household survey dataset collected from different regions in rural China, we estimated the share of households deprived in each poverty dimension, headcount ratio, and adjusted multidimensional poverty incidence. Furthermore, we employed the endogenous switching regression (ESR) model to examine the impact of mobile Internet use on multidimensional poverty.

The present study contributes to the existing literature on ICT adoption and poverty reduction by examining the nexus between mobile Internet use and multidimensional poverty from four aspects. First, to our knowledge, this is the first study to examine the association between mobile Internet use and poverty reduction. Much of the literature on the role of ICTs in poverty reduction has paid particular attention to broadband Internet, mobile phones, and mobile money (Fu \& Akter, 2016; Mora-Rivera \& García-Mora, 2021; Munyegera \& Matsumoto, 2018). However, very few studies have empirically analyzed the impact of mobile Internet on reducing poverty. Mobile Internet can help rural households strengthen social networks, update their knowledge and access to employment opportunities, and thereby it has the potential to allow rural households to benefit from mobile Internet accessibility. Analyzing the impact of mobile Internet use will assist in our understanding of the role of mobile ICTs in reducing poverty.

Second, we investigated the effect of mobile Internet use on multidimensional poverty, including both objective and subjective wellbeing dimensions in the poverty measurement. Many previous studies on multidimensional poverty measurement have mainly adopted objective wellbeing dimensions such as education, health, and living standards (Alkire \& Seth, 2015; Santos \& Villatoro, 2018), while subjective wellbeing dimensions such as overall satisfaction and happiness are overlooked. Incorporating subjective and objective wellbeing dimensions in multidimensional poverty will give a better understanding of the effect of mobile Internet use on poverty reduction.

Third, we employed an ESR model, which accounts for potential endogeneity stemming from both observed and unobserved factors, to address selection bias in the impact assessment of mobile Internet use. A propensity score matching method used in several studies explored the effects of ICTs on household welfare (Mora-Rivera \& García-Mora, 2021; Munyegera \& Matsumoto, 2016; Zheng \& Lu, 2021). However, the limitation of this method is that it only controls the selection bias coming from observed characteristics. Some studies employed panel estimation techniques to examine the causality relationship between intervention variables and poverty (Bekun \& Akadiri, 2019; Mushtaq \& Bruneau, 2019), but this method cannot estimate the treatment effects of intervention variables on poverty.

Fourth, we examined heterogeneity of the impact of mobile Internet use on multidimensional poverty among regions with different economic levels. A few studies held the view that ICTs facilitated inclusive development (Mora-Rivera \& García-Mora, 2021; Qiang et al., 2009), while other studies concluded that ICTs increased the digital divide because of the wide differences in infrastructure and income levels of different regions (van Deursen \& van Dijk, 2019). Given the mixed findings of previous studies, we attempt to provide more evidence by investigating the heterogeneous effects of mobile Internet use among different regions.

The paper's remaining parts proceed as follows. Section 2 presents the theoretical context, and measurement of key variables are introduced in Sect. 3. Section 4 presents the ESR model, which is used as an estimation strategy in this study. The results of descriptive statistics, multidimensional poverty measurement and the effect of mobile Internet use on multidimensional poverty are in Sect. 5. Finally, we conclude the main findings and highlight policy implications. 


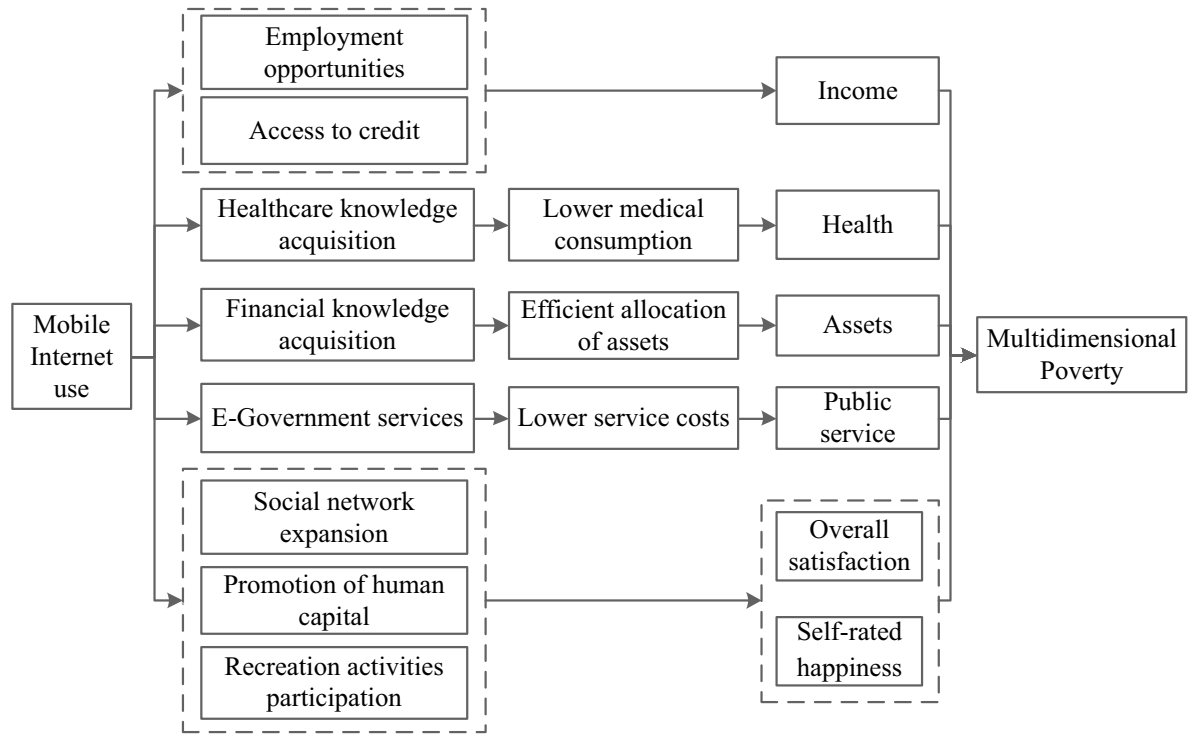

Fig. 1 Relationship between mobile Internet use and multidimensional poverty

\section{Theoretical Context}

Poverty is a complex and broad social phenomenon, including both objective and subjective wellbeing. However, previous studies have measured poverty mainly using dimensions of income, consumption, or other monetary dimensions (Masanjala, 2006; Park \& Wang, 2010), due to the characteristics of easy measurement and ease of international comparisons. In recent studies, researchers tend to use multiple dimensions to measure and understand poverty, referred to as multidimensional poverty (Abeje et al., 2020; Pomati \& Nandy, 2020). According to the perspective of multidimensional poverty, poverty includes not only monetary dimensions, but also non-monetary dimensions such as living standards (e.g. water, electricity, sanitation facilities), social security, and subjective perception. Thus, we argue that measurement of multidimensional poverty will depict a comprehensive status of household welfare and alleviating multidimensional poverty will help reduce inequality and improve the wellbeing of low-income groups from an integrated perspective.

In recent years, globally available mobile Internet has functioned directly in reducing transaction costs, providing access to current information, strengthening social networks, and increasing productivity. Against this background, we argue that mobile Internet use may affect multidimensional poverty reduction via a variety of potential mechanisms. A conceptual framework of the potential mechanisms that connect mobile Internet use with multidimensional poverty is illustrated in Fig. 1.

For the objective wellbeing dimensions, mobile Internet use may help rural households increase income through access to more employment opportunities. For example, employment mobile apps are emerging with widespread use of mobile Internet. Mobile apps can eliminate information asymmetry in the labor market and rural households can find more employment information, contributing to household income growth. Moreover, mobile Internet use helps rural households access online credit, thereby relaxing financial constraints, and encouraging rural inhabitants to participate in new income-increasing 
activities. This may also contribute to increasing the possibilities of obtaining higher income. In addition to the dimension of income, the framework also reveals that mobile Internet can enable rural households to acquire healthcare knowledge through online medical lectures or healthcare-related mobile apps, which helps rural households reduce medical expenditures and improve their health. Furthermore, Fig. 1 shows that mobile Internet use can decrease the likelihood of falling into asset poverty via acquiring financial knowledge and efficiently allocating assets. This potential mechanism is consistent with previous studies showing that ICT use will help adults facilitate their literacy and numeracy (Deshpande et al., 2017); higher financial literacy has a positive effect on financial outcome (Chu et al., 2017). With regard to the dimension of public service, governments can use mobile Internet to offer e-government applications and decrease service costs, enabling convenient access to public services in rural households.

Regarding the subjective wellbeing dimensions, interpersonal communication is an important way for people to obtain social and economic resources and maintain social networks. Mobile Internet use can promote interpersonal communication and interaction at relatively low cost, resulting in enlarging individual online social networks, and thereby helping rural households improve satisfaction and self-rated happiness. Moreover, rural households can use mobile Internet to search for skill training courses, participate in distance learning to enhance personal skills, and promote human capital, contributing to an increase in satisfaction and happiness. Furthermore, mobile Internet use can also enhance rural households' overall satisfaction and self-rated happiness through online recreation activities such as chatting with friends, playing online games, watching free entertainment programs, and browsing forums. For example, in a study on COVID-19, researchers found that community-level quarantine decreased personal happiness (Lu et al., 2020), while mobile Internet use reduced the negative impact of community-level quarantine on happiness through participation in online recreation activities.

Based on the potential mechanisms illustrated in Fig. 1, we assume that mobile Internet use affects rural households' different dimensions of income, health, assets, public service, overall satisfaction, and self-rated happiness, resulting in a synthesis effect on multidimensional poverty. Despite the theoretical analysis, the impact of mobile Internet use on multidimensional poverty has never been empirically examined. Therefore, the present study investigated, for the first time, the impact of mobile Internet use on multidimensional poverty using a rigorous econometric analysis.

\section{Data and Measures}

\subsection{Data}

The data used in this study were collected from three provinces in China in January 2019. To select observation units, we employed a multistage sampling procedure. First, we chose three provinces, Sichuan, Henan, and Fujian, from different parts of China. Second, two counties were randomly selected from each province: Pengshan and Pengzhou counties in Sichuan province; Lingbao and Qi counties in Henan province; and Jiaocheng and Yongtai counties in Fujian province. Third, two towns were randomly selected from each county. Fourth, we randomly chose three villages from each town. Finally, around 15 to 25 households including mobile Internet users and non-users were interviewed randomly in each 
village. A total of 820 rural households including 549 mobile Internet users and 271 nonusers were used in the analysis.

\subsection{Measuring Mobile Internet use}

The binary variable of mobile Internet use is the core independent variable, which is equal to one if a rural household uses mobile Internet, and zero otherwise. For accuracy of measurement, we measured mobile Internet use based on the indicators of smartphone use and expense of mobile Internet. Several rural households can use the Internet on their smartphones. However, we cannot ensure that they are the mobile Internet users, because they only use the Internet when having access to WIFI hotspots established by other households. In this study, the variable of mobile Internet use is one when households use Internet on smartphones, and they have expenditure on mobile Internet.

\subsection{Measuring Multidimensional Poverty}

To measure multidimensional poverty, we followed the method proposed by Alkire and Foster (2011), which has been widely used in a number of existing studies (Nowak \& Scheicher, 2017; Ogutu \& Qaim, 2019). The procedures for measuring multidimensional poverty are as follows:

First, denoting a $n \times d$ matrix $y=\left[Y_{i j}\right]$, where $Y_{i j}$ represents the value of household $i$ in dimension $j, n$ represents sample size, and $d$ represents the number of dimensions. Second, selecting the cut-off for each dimension and denoting $Z_{i}$ as the cut-off value for dimension $j$. Third, denoting a deprivation matrix $g^{0}=\left[g_{i j}^{0}\right]$, where $g_{i j}^{0}=1$ if $Y_{i j}<Z_{i}$, and $g_{i j}^{0}=0$ otherwise. Fourth, denoting a column vector $c_{i}=\left[g^{0}\right]$, which represents the total number of deprived dimensions for household $i$. Fifth, denoting $k$ as the poverty cut-off. Sixth, denoting $\rho_{k}$ as the function used to identify the multidimensionally poor, where $\rho_{k}\left(y_{i} ; z\right)=1$ if $c_{i} \geq k$, and $\rho_{k}\left(y_{i} ; z\right)=0$ otherwise. Finally, we can calculate the multidimensional poverty headcount ratio:

$$
H=q / n
$$

where $q$ is the number of the multidimensionally poor identified by $\rho_{k}$, and $n$ is the sample size.

Given that $H$ is not sensitive to additional deprived dimensions of the multidimensionally poor, Alkire and Foster (2011) proposed another index, i.e., adjusted multidimensional poverty incidence $M_{0}$, which can be expressed as follows:

$$
M_{0}=H A
$$

where $A$ is the average deprivation share across the multidimensionally poor and $A=\sum_{1}^{n} C_{i} / n d$.

The dimensions and indicators used in the multidimensional poverty measurement are presented in Table 1. For dimensions selected in the measurement, income, health, assets, and public service were used to represent objective wellbeing, while overall satisfaction and happiness were employed to measure subjective wellbeing. We used different indicators to operationalize the measurement for selected dimensions and choose appropriate cut-offs for each dimension. Based on the identification for each dimension, the number of deprived dimensions can be calculated for each household. If the number of deprived 


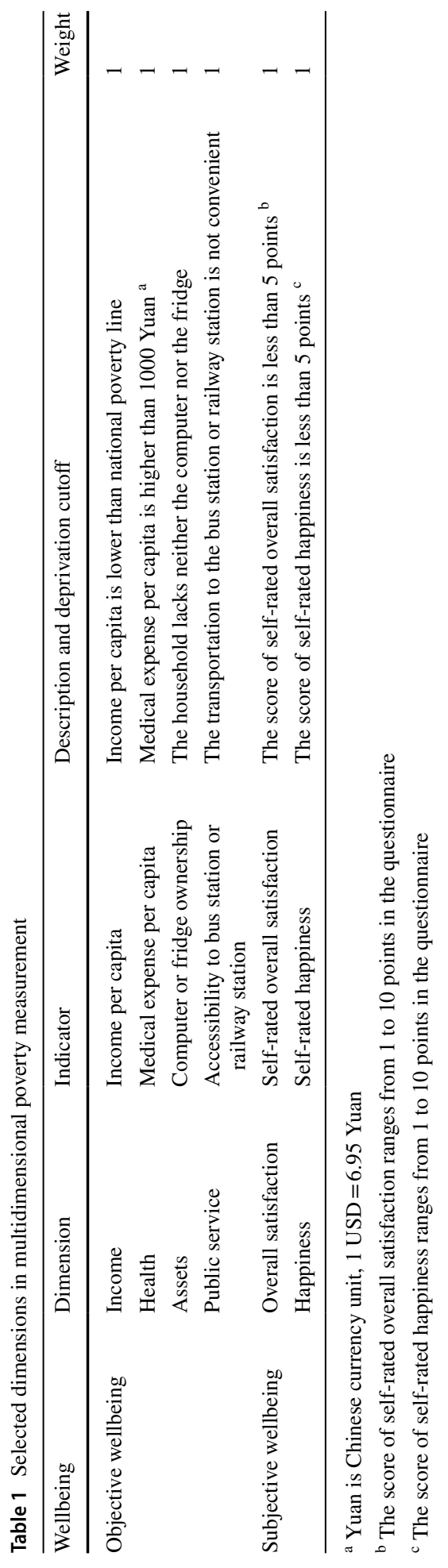


dimensions is greater than or equal to a certain threshold, namely poverty cut-off, the household will be identified as multidimensionally poor. We used 3 as the poverty cut-off in the present study. Finally, we calculated multidimensional poverty headcount ratio $H$ and adjusted multidimensional poverty incidence $M_{0}$ based on identification as multidimensionally poor.

In this study, multidimensional poverty is the dependent variable used in the econometric method. However, both $H$ and $M_{0}$ are aggregated indices, and are thus not appropriate to use in the econometric method. To solve this problem, following Ogutu and Qaim (2019), we employed the total number of deprived dimensions in the present study to represent the dependent variable of multidimensional poverty used in the econometric method. To test the robustness of the results, we also used different measurements of poverty, e.g. each poverty dimension, as outcome variables and examined the impact of mobile Internet on multidimensional poverty.

\section{Method and Estimation Strategy}

The aim of the present study was to investigate the effect of mobile Internet use on multidimensional poverty. If mobile Internet use is exogenous, ordinary least square (OLS) regression can be used directly to examine this effect. However, selection bias originating from observed factors and unobserved factors may occur because households generally decide whether to use mobile Internet by themselves. This is a common source of endogeneity. To solve the problem of endogeneity, following Ngoma (2018), we employed the endogenous switching regression (ESR) model to examine the impact of mobile Internet use on multidimensional poverty.

\subsection{The ESR Model}

Under the ESR model framework, we estimated household $i$ 's decision on mobile Internet use by employing a binary probit model in the first step. Household $i$ 's decision on mobile Internet use can be expressed as:

$$
U_{i}^{*}=Z_{i} \beta+\mu_{i}, \quad U_{i}=1 \text { if } U_{i}^{*}>0
$$

where $U_{i}^{*}$ represents the difference between the potential return of mobile Internet use and non-use for household $i . U_{i}$ is a dichotomous variable and $U_{i}=1$ if household $i$ chooses to use mobile Internet, while $U_{i}=0$ otherwise. $Z_{i}$ is a vector representing household characteristics. $\beta$ represents the parameters and $\mu_{i}$ is an error term.

In the second step, we can specify two outcome equations for mobile Internet users and non-users as:

$$
\begin{aligned}
& \text { Regime 1: } Y_{i 1}=X_{i} \beta_{i 1}+\varepsilon_{i 1} \text { if } U_{i}=1 \\
& \text { Regime 2: } Y_{i 0}=X_{i} \beta_{i 0}+\varepsilon_{i 0} \text { if } U_{i}=0
\end{aligned}
$$

where $Y_{i 1}$ and $Y_{i 0}$ are outcome variables respectively representing the number of deprived dimensions and each poverty dimension for household $i . X_{i}$ represents exogenous variables. $\beta_{i 1}$ and $\beta_{i 0}$ are parameters to be estimated. $\varepsilon_{i 1}$ and $\varepsilon_{i 0}$ are random disturbance terms. 
Selection bias should not be ignored due to the correlation between $\varepsilon_{i 1}$ and $\varepsilon_{i 0}$ in Eqs. (4) and (5) and $\mu_{i}$ in the selection Eq. (3). To address selection bias, we can estimate the selection Eq. (3) and calculate the Inverse Mills Ratios (IMRs) $\lambda_{i 1}$ and $\lambda_{i 0}$. Then $\lambda_{i 1}$ and $\lambda_{i 0}$ are included in outcome Eqs. (4) and (5) as follows:

$$
\begin{aligned}
& Y_{i 1}=X_{i} \beta_{i 1}+\sigma_{\mu 1} \lambda_{i 1}+\gamma_{i 1} \text { if } U_{i}=1 \\
& Y_{i 0}=X_{i} \beta_{i 0}+\sigma_{\mu 0} \lambda_{i 0}+\gamma_{i 0} \text { if } U_{i}=0
\end{aligned}
$$

where $\sigma_{\mu 1}=\operatorname{cov}\left(\mu_{i}, \varepsilon_{i 1}\right)$ and $\sigma_{\mu 0}=\operatorname{cov}\left(\mu_{i}, \varepsilon_{i 0}\right)$, the Inverse Mills Ratios (IMRs) $\lambda_{i 1}=\frac{\phi\left(Z_{i} \hat{\beta}\right)}{\Phi\left(Z_{i} \hat{\beta}\right)}, \lambda_{i 0}=\frac{\phi\left(Z_{i} \hat{\beta}\right)}{1-\Phi\left(Z_{i} \hat{\beta}\right)}$, and $\gamma_{i 1}$ and $\gamma_{i 0}$ are error terms.

For identification purposes in the ESR model, $Z_{i}$ in Eq. (3) should contain the variables in $X_{i}$ plus at least one instrumental variable. These instrumental variables can explain the probability of the household choosing to use mobile Internet, but should not have significant effects on multidimensional poverty. In the present study, the variables representing home delivery service and a friend's adoption of online shopping are selected as instrumental variables. To test the validity of the selected instrumental variables, we employed a probit model to test if the household's decision to use mobile Internet is significantly affected by home delivery service or a friend's adoption of online shopping. In addition, we used OLS regression to test whether the instrumental variables have significant effects on multidimensional poverty. Column (1) in Appendix Table 11 shows the results of probit model estimation. The significant coefficients of home delivery service and a friend's adoption of online shopping in the probit model suggest that home delivery service and a friend's adoption of online shopping significantly affect mobile Internet use. Column (2) in Appendix Table 11 shows the results of OLS regression, and the coefficients of home delivery service and a friend's adoption of online shopping are not statistically significant, revealing that home delivery service and a friend's adoption of online shopping do not affect multidimensional poverty.

Furthermore, we used the Sargan test, a test of overidentifying restrictions, to examine the correlation between the instrumental variables and error terms (Sargan, 1958). The result of the Sargan test is $\operatorname{Pr}>\chi^{2}(1)=0.2305$, affirming that the instrumental variables are uncorrelated with the error terms. Moreover, an $F$ test was used to check the joint significance of the instrumental variables, which can help test the hypothesis of weak instrumental variables. The result of the $F$ test is 10.9459 and the $P$ value is 0.0000 , suggesting that the null hypothesis of weak instrumental variables is rejected, and the instrumental variables selected in the present study are not weak instrumental variables. These findings confirm the validity of home delivery service and a friend's adoption of online shopping as instrumental variables.

\subsection{Estimating Treatment Effects}

By comparing the expected values of the outcomes of mobile Internet users and the counterfactual group, we can calculate the average treatment effect on the treated (ATT) based on the ESR framework (Khonje et al., 2015). The ATT can be calculated as follows:

Mobile Internet users (observed in the sample):

$$
E\left[Y_{i 1} \mid T=1\right]=X_{i} \beta_{i 1}+\sigma_{\mu 1} \lambda_{i 1}
$$

If mobile Internet users had not used mobile Internet (counterfactual group): 


$$
E\left[Y_{i 0} \mid T=1\right]=X_{i} \beta_{i 0}+\sigma_{\mu 0} \lambda_{i 1}
$$

Thus, ATT of mobile Internet users can be derived from the difference between Eqs. (8) and (9):

$$
A T T=E\left[Y_{i 1} \mid T=1\right]-E\left[Y_{i 0} \mid T=1\right]=X_{i}\left(\beta_{i 1}-\beta_{i 0}\right)+\left(\sigma_{\mu 1}-\sigma_{\mu 0}\right) \lambda_{i 1}
$$

\section{Results}

\subsection{Descriptive Statistics}

Table 2 presents descriptive statistics for the explanatory variables included in the econometric model. Specific definitions of the variables are presented in the second column. These selected explanatory variables are based on the existing literature related to adopting ICTs and household welfare (Alalwan et al., 2018). About $67 \%$ of the respondents are mobile Internet users. The average education level of the respondents is 6.83 years, suggesting that the rural respondents have a relatively low education level. About $84 \%$ of the respondents are risk averse, indicating that most are unlikely to engage in risky economic activities. In addition, Table 2 shows that $90 \%$ of the sample households have access to credit from their friends or financial institutions, while $18 \%$ of the sample households have cooperative membership.

Table 3 shows the results of comparing mean values for household characteristics between mobile Internet users and non-users. The results reveal that households using mobile Internet may systematically differ from non-users. Specifically, the difference of average age between mobile Internet users and non-users is significantly negative, indicating that mobile Internet users tend to be younger than non-users. Compared to female respondents in the sample, male respondents tend to use mobile Internet. Mobile Internet users are more likely to have a higher education level and are less likely to be risk averse. In addition, the mean difference of the variable representing access to credit is positive and statistically significant, suggesting that mobile Internet users tend to have access to credit relative to non-users. It is not unexpected to see that rural households far from agricultural markets are more likely to use mobile Internet, because mobile Internet can help them access market information, decrease transaction costs, and strengthen social networks, which may balance the negative effect of the greater distance from markets. The results also show that households in Henan province tend to use mobile Internet, while those who live in Sichuan province are less likely to use it.

\subsection{Results of Multidimensional Poverty Measurement}

The share of households considered deprived in each poverty dimension is presented in Table 4. The results show that $4.39 \%$ of the sample households are deprived in terms of the dimension of income, which is lower than other dimensions. Table 4 also reveals that about $37.56 \%$ of households are deprived in the dimension of public service, representing accessibility to bus or railway stations. Moreover, Table 4 also reveals that the share of households deprived in the dimensions of assets, overall satisfaction, and happiness are approximately $10 \%$, also higher than the share of the dimension of income. 


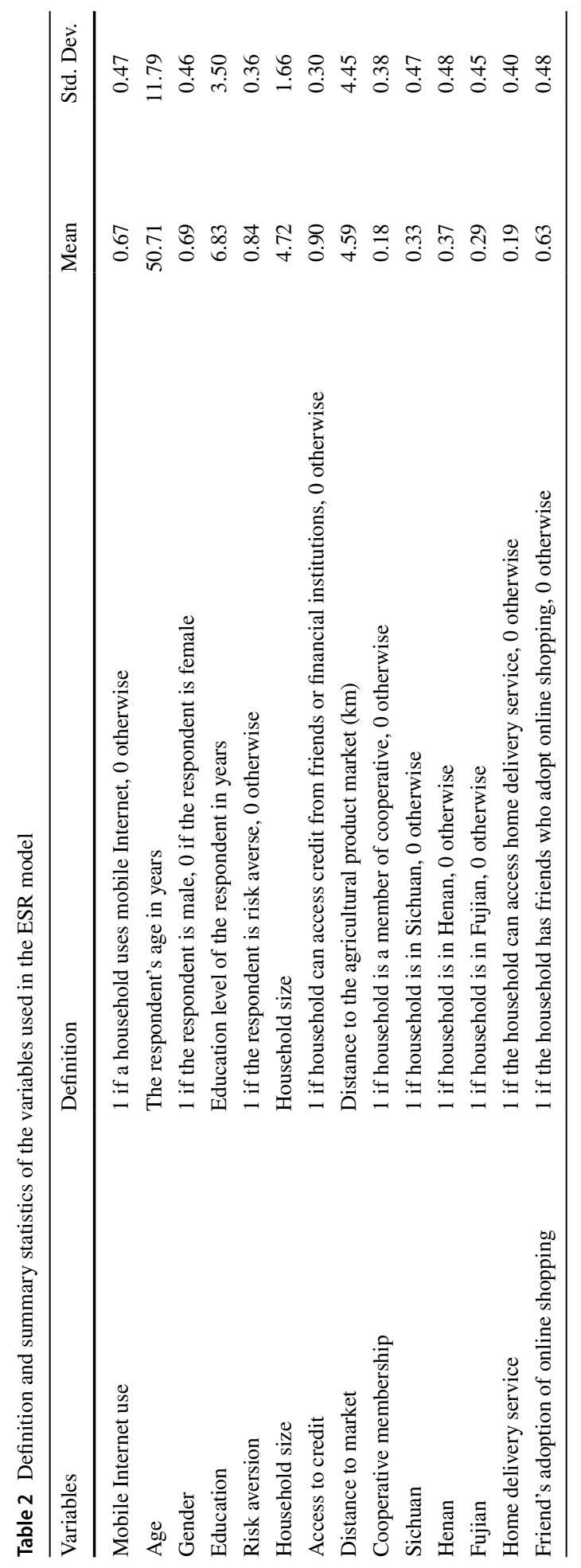


Table 3 Mean differences in characteristics between mobile Internet users and non-users

\begin{tabular}{lrrrr}
\hline Variable & \multicolumn{1}{l}{ Users } & \multicolumn{1}{l}{ Non-users } & \multicolumn{1}{c}{ Difference } & t-statistic \\
\hline Age & $45.50(0.39)$ & $61.25(0.58)$ & $-15.75^{* * * *}$ & -23.13 \\
Gender & $0.74(0.02)$ & $0.59(0.03)$ & $0.14^{* * * *}$ & 4.22 \\
Education & $7.90(0.13)$ & $4.66(0.21)$ & $3.24^{* * *}$ & 13.87 \\
Risk aversion & $0.81(0.02)$ & $0.92(0.02)$ & $-0.11^{* * * *}$ & -4.19 \\
Household size & $4.77(0.07)$ & $4.62(0.11)$ & 0.15 & 1.22 \\
Access to credit & $0.92(0.01)$ & $0.87(0.02)$ & $0.05^{* * *}$ & 2.30 \\
Distance to market & $5.28(0.21)$ & $3.20(0.18)$ & $2.09^{* * *}$ & 6.48 \\
Cooperative membership & $0.19(0.02)$ & $0.16(0.02)$ & 0.03 & 1.02 \\
Sichuan & $0.18(0.02)$ & $0.65(0.03)$ & $-0.47^{* * * *}$ & -15.21 \\
Henan & $0.53(0.02)$ & $0.05(0.01)$ & $0.48^{* * *}$ & 15.17 \\
Fujian & $0.29(0.02)$ & $0.30(0.03)$ & -0.01 & -0.33 \\
Home delivery service & $0.20(0.02)$ & $0.18(0.02)$ & 0.03 & 0.85 \\
Friend's adoption of online shopping & $0.76(0.02)$ & $0.35(0.03)$ & $0.41^{* * * *}$ & 12.61 \\
\hline
\end{tabular}

Standard errors are in parentheses, $* * p<0.05, * * * p<0.01$

Table 4 The share of households deprived in each poverty dimension

\begin{tabular}{llll}
\hline Wellbeing & Dimension & Share & Std. Dev. \\
\hline Objective wellbeing & Income deprivation & 0.0439 & 0.2050 \\
& Health deprivation & 0.2890 & 0.4536 \\
& Assets deprivation & 0.1012 & 0.3018 \\
Subjective wellbeing & Public service deprivation & 0.3756 & 0.4846 \\
& Overall satisfaction deprivation & 0.1098 & 0.3128 \\
& Happiness deprivation & 0.1061 & 0.3082 \\
\hline
\end{tabular}

Table 5 Multidimensional poverty index among full sample, mobile Internet users, and non-users

\begin{tabular}{lllc}
\hline Multidimensional poverty index & Full sample & Users & Non-users \\
\hline Multidimensional poverty headcount ratio $(H)$ & 0.0963 & 0.0838 & 0.1218 \\
Adjusted multidimensional poverty incidence $\left(M_{0}\right)$ & 0.0547 & 0.0458 & 0.0726 \\
\hline
\end{tabular}

Table 5 presents the results of multidimensional poverty measurement. Multidimensional poverty headcount ratio of the full sample is 0.0963 , suggesting that $9.63 \%$ of the sample households are multidimensionally poor ones. The multidimensional poverty headcount ratio is higher than income poverty ratio, which is shown in Table 4, indicating that we may underestimate the poverty rate if we select income poverty measurement. The finding is consistent with the study of Alkire and Foster (2011), which revealed that the traditional income poverty rate is lower than the multidimensional poverty rate in the United States. We also find that adjusted multidimensional poverty 
Table 6 Mean differences in poverty dimensions between mobile Internet users and non-users

\begin{tabular}{llllr}
\hline Variable & Users & Non-users & Difference & t-statistic \\
\hline Multidimensional deprivation & $0.08(0.01)$ & $0.12(0.02)$ & $-0.04^{*}$ & -1.74 \\
Income deprivation & $0.03(0.01)$ & $0.08(0.02)$ & $-0.05^{* * *}$ & -3.69 \\
Health deprivation & $0.28(0.02)$ & $0.31(0.03)$ & -0.03 & -1.09 \\
Assets deprivation & $0.06(0.01)$ & $0.18(0.02)$ & $-0.12^{* * *}$ & -5.40 \\
Public service deprivation & $0.41(0.02)$ & $0.31(0.03)$ & $0.10^{* * *}$ & 2.89 \\
Overall satisfaction deprivation & $0.12(0.01)$ & $0.10(0.02)$ & 0.02 & 0.89 \\
Happiness deprivation & $0.10(0.01)$ & $0.12(0.02)$ & -0.02 & -1.02 \\
\hline
\end{tabular}

Multidimensional deprivation is a binary variable, which equals 1 if a household is multidimensionally poor and 0 otherwise. Standard errors are in parentheses, $* p<0.1, * * * p<0.01$

incidence of the full sample households is 0.0547 , indicating that the share of multidimensionally poor households' deprived dimensions is $5.47 \%$.

Table 5 also shows the results of the multidimensional poverty index for mobile Internet users and non-users. The results reveal that the multidimensional poverty headcount ratio of mobile Internet users is 0.0838 , indicating that $8.38 \%$ of mobile Internet users are multidimensionally poor households. The multidimensional poverty headcount ratio of users is lower than that of non-users, suggesting that mobile Internet use may decrease multidimensional poverty headcount ratio. In addition, we also find that adjusted multidimensional poverty incidence of mobile Internet users is lower than that of non-users, suggesting that mobile Internet use may have a negative impact on multidimensional poverty.

Furthermore, we also analyze the mean difference of poverty dimensions between users and non-users (Table 6). The results show that the difference of multidimensional deprivation ${ }^{1}$ between users and non-users is negative and statistically significant, suggesting that mobile Internet users are less likely to be multidimensionally poor households than nonusers. For the dimension of income, the significantly negative mean difference between users and non-users indicates that mobile Internet use may decrease the possibility of falling into income poverty. In addition, the results also show that mobile Internet users are less likely to fall into health poverty relative to non-users, but the mean difference is not statistically significant.

For the dimension of assets, Table 6 shows that the mean difference is negative and statistically significant, indicating that mobile Internet users have a lower possibility of being asset poor households. Interestingly, the mean difference of the dimension of public service is significantly positive, revealing that mobile Internet users tend to be deprived in the dimension of public service. This may be attributed to the problem of self-selection, that is, rural households far from markets are more likely to use mobile Internet. Regarding the dimensions of overall satisfaction and self-rated happiness, the results show that the mean differences are not statistically significant, suggesting that mobile Internet use may not have significant effects on rural households' subjective wellbeing.

Table 7 presents the results of a correlation analysis among mobile Internet use and poverty dimensions. We found a negative and statistically significant correlation between

\footnotetext{
1 Multidimensional poverty headcount ratio and adjusted multidimensional poverty incidence are aggregate indices, while multidimensional deprivation is a binary variable that equals 1 if a household is multidimensionally poor and 0 otherwise.
} 
Table 7 Pearson correlation analysis among mobile Internet use and poverty dimensions

\begin{tabular}{|c|c|c|c|c|c|c|c|c|}
\hline Variable & (1) & (2) & (3) & (4) & (5) & (6) & (7) & (8) \\
\hline (1) Mobile Internet use & 1.00 & & & & & & & \\
\hline $\begin{array}{l}\text { (2) Multidimensional depriva- } \\
\text { tion }\end{array}$ & $-0.06^{*}$ & 1.00 & & & & & & \\
\hline (3) Income deprivation & $-0.13 * * *$ & $0.17 * * *$ & 1.00 & & & & & \\
\hline (4) Health deprivation & -0.04 & $0.20 * * *$ & 0.02 & 1.00 & & & & \\
\hline (5) Assets deprivation & $-0.19 * * *$ & $0.23 * * *$ & $0.07 *$ & -0.03 & 1.00 & & & \\
\hline (6) Public service deprivation & $0.10 * * *$ & $0.31 * * *$ & 0.02 & $0.06^{*}$ & -0.01 & 1.00 & & \\
\hline $\begin{array}{l}\text { (7) Overall satisfaction depriva- } \\
\text { tion }\end{array}$ & 0.03 & $0.67 * * *$ & 0.04 & $0.08 * *$ & 0.05 & $0.17 * * *$ & 1.00 & \\
\hline (8) Happiness deprivation & -0.04 & $0.72 * * *$ & $0.06^{*}$ & $0.06^{*}$ & $0.09 * *$ & $* 0.18 * * *$ & $0.70 * *$ & 1.00 \\
\hline
\end{tabular}

Multidimensional deprivation is a binary variable, which equals 1 if a household is multidimensionally poor and 0 otherwise. $* x<0.1, * * p<0.05$, *** $p<0.01$

mobile Internet use and multidimensional deprivation, suggesting that mobile Internet use may decrease the possibility of rural households falling into multidimensional poverty. The finding is consistent with the descriptive analysis in Tables 5 and 6 . In addition, the results reveal that income deprivation is negatively correlated with mobile Internet use, indicating that mobile Internet use can reduce income poverty. The Pearson's correlation coefficient is -0.19 between mobile Internet use and asset deprivation and the coefficient is statistically significant, suggesting that mobile Internet use has a negative effect on asset deprivation. Regarding overall satisfaction and self-rated happiness, the correlation coefficients are not statistically significant, indicating that mobile Internet use has no significant effect on subjective wellbeing. However, given that households generally decide for themselves whether or not to use mobile Internet, the descriptive and correlation analysis may be misleading because of potential selection bias. To control for the potential bias, rigorous econometric methods such as the ESR model can be employed to examine the effect of mobile Internet use on multidimensional poverty.

\subsection{Results of ESR Estimation}

Estimates for the factors affecting mobile Internet use are shown in Column (1) in Table 8. Age squared appears to have a negative and statistically significant coefficient in the selection equation, suggesting that an inverted U-shaped relationship may exist between the variables of age and mobile Internet use. There seems to be a positive and significant association between the variables of education and mobile Internet use, indicating that respondents with a higher education level tend to be mobile Internet users. Better education means enhanced ability and better understanding of new ICTs and therefore the likelihood of using mobile Internet may rise with education. The finding is in line with MartínezDomínguez and Mora-Rivera (2020) who found that people with higher education levels tend to have access to mobile Internet in rural Mexico.

The variable representing distance to market also positively influences mobile Internet use decisions, indicating that households with greater distances to the market tend to be mobile Internet users. A greater distance to market results in more difficulties in communication and higher transaction costs. However, access to mobile Internet can 
Table 8 Determinants of mobile Internet use and multidimensional poverty

\begin{tabular}{|c|c|c|c|}
\hline \multirow[t]{2}{*}{ Variables } & \multirow[t]{2}{*}{ Selection Eq. (1) } & \multicolumn{2}{|c|}{ The number of deprived dimensions } \\
\hline & & Users (2) & Non-users (3) \\
\hline Age & $0.067(0.060)$ & $-0.016(0.043)$ & $-0.170(0.095)^{*}$ \\
\hline Age squared & $-0.001(0.001)^{* *}$ & $0.000(0.000)$ & $0.001(0.001)^{* *}$ \\
\hline Gender & $0.156(0.141)$ & $-0.057(0.104)$ & $-0.209(0.154)$ \\
\hline Education & $0.115(0.022)^{* * *}$ & $-0.031(0.018)^{*}$ & $-0.022(0.026)$ \\
\hline Risk aversion & $-0.230(0.202)$ & $-0.256(0.123)^{* *}$ & $-0.116(0.268)$ \\
\hline Household size & $0.036(0.038)$ & $-0.087(0.028)^{* * *}$ & $-0.118(0.037)^{* * *}$ \\
\hline Access to credit & $-0.090(0.204)$ & $-0.312(0.163)^{*}$ & $-0.399(0.245)$ \\
\hline Distance to market & $0.035(0.019)^{*}$ & $0.042(0.009) * * *$ & $0.038(0.031)$ \\
\hline Cooperative membership & $-0.019(0.160)$ & $-0.025(0.100)$ & $0.050(0.161)$ \\
\hline Henan & $0.989(0.202)^{* * *}$ & $0.253(0.166)$ & $0.489(0.468)$ \\
\hline Fujian & $0.722(0.157)^{* * *}$ & $0.359(0.172)^{* *}$ & $0.699(0.202)^{* * *}$ \\
\hline Home delivery service & $0.268(0.151)^{*}$ & & \\
\hline Friend's adoption of online shopping & $0.528(0.127)^{* * *}$ & & \\
\hline Inverse Mill's ratio & & $-0.048(0.307)$ & $-0.235(0.412)$ \\
\hline Constant & $-1.245(1.691)$ & $2.035(1.157)^{*}$ & $6.554(3.200)^{* * *}$ \\
\hline Log pseudolikelihood & -261.616 & & \\
\hline Wald $\chi^{2}(13)$ & 306.11 & & \\
\hline Pseudo $\mathrm{R}^{2}$ & 0.497 & & \\
\hline Observations & 820 & 549 & 271 \\
\hline
\end{tabular}

The reference region is Sichuan. Standard errors are in parentheses, $* p<0.1, * * p<0.05, * * * p<0.01$

help households establish connections with the market and engage in commercial activities online and therefore reduce adverse effects caused by greater distance to market. Thus, households far from the market have a higher probability to use mobile Internet. Moreover, the coefficients of location variables (e.g. Henan and Fujian) are positive and statistically significant, indicating the presence of location effects that affect the household's decision on mobile Internet use. In particular, our estimates show that compared with households located in Sichuan (reference group), households in Henan and Fujian tend to have a higher probability of mobile Internet use.

Columns (2) and (3) in Table 8 show the results of determinants of multidimensional poverty for users and non-users. The estimates suggest that the factors affecting multidimensional poverty of mobile Internet users and non-users are different. The finding is in line with previous studies, which showed that the factors affecting outcome variables for treatment group and control group were different under the framework of the ESR model (Shiferaw et al., 2014). In the present study, the variables representing education, risk aversion, household size, access to credit, distance to market, and location have statistically significant impacts on multidimensional poverty of mobile Internet users. By contrast, for non-users, the multidimensional poverty is affected by the variables of age, household size, and location. In addition, these estimates also imply that it is reasonable to employ the ESR model to analyze factors affecting multidimensional poverty separately for mobile Internet users and non-users. 
Table 9 Average treatment effects on the treated (ATT) of mobile Internet use on multidimensional poverty for the full sample

\begin{tabular}{|c|c|c|c|c|}
\hline \multirow[t]{2}{*}{ Group } & \multicolumn{2}{|l|}{ Mean outcomes } & \multirow[t]{2}{*}{ ATT } & \multirow[t]{2}{*}{ t-value } \\
\hline & Users & Counterfactual & & \\
\hline Number of deprived dimensions & $0.989(0.014)$ & $1.790(0.026)$ & $-0.801 * * *$ & -27.320 \\
\hline Income & $20,264.094(401.788)$ & $12,637.525(442.398)$ & $7626.569 * * *$ & 12.761 \\
\hline Health & $1305.379(36.816)$ & $1370.726(46.613)$ & -65.348 & -1.100 \\
\hline Assets & $0.938(0.002)$ & $0.934(0.005)$ & 0.004 & 0.641 \\
\hline Public service & $0.590(0.009)$ & $0.299(0.014)$ & $0.291 * * *$ & 17.890 \\
\hline Overall satisfaction & $6.933(0.030)$ & $5.973(0.040)$ & $0.959 * * *$ & 19.414 \\
\hline Happiness & $7.297(0.030)$ & $6.229(0.045)$ & $1.068 * * *$ & 19.895 \\
\hline
\end{tabular}

Standard errors are in parentheses, $* * * p<0.01$

Table 9 shows the results of ATT of mobile Internet use on multidimensional poverty. The results show that mobile Internet use significantly decreases multidimensional poverty. In particular, the mean number of deprived dimensions for mobile Internet users is 0.989 , while the mean outcome is 1.790 if the users do not choose to use mobile Internet. The ATT of mobile Internet use on multidimensional poverty is negative and statistically significant, indicating that mobile Internet users have significantly less deprived dimensions relative to non-users. The finding of the negative relationship between mobile Internet use and poverty is consistent with the study of Fu and Akter (2016), who found that mobile phone technology significantly reduced poverty by improving farmers' agricultural knowledge and access to credit.

To test the robustness of the results, in addition to the number of deprived dimensions representing multidimensional poverty in the aggregate, we investigated the impact of mobile Internet use on each poverty dimension. The estimates show that the ATT of mobile Internet on household income per capita is positive and statistically significant, suggesting that mobile Internet use can significantly increase household income and lower income poverty incidence. Moreover, the ATT of mobile Internet on public service is positive and statistically significant, implying that mobile Internet can help users access public services. With respect to the dimensions of overall satisfaction and happiness, the ATTs are also positive and statistically significant, revealing that mobile Internet use can help increase subjective wellbeing. Unlike the dimensions of income, public service, and subjective wellbeing, the ATT of mobile Internet use on the dimensions of health and assets are not statistically significant, which may be attributed to the hysteresis effect of mobile Internet use on health and assets. On the whole, mobile Internet use can significantly increase household income and improve access to public services and subjective wellbeing, suggesting that mobile Internet use has significant effects on multidimensional poverty reduction.

\subsection{Heterogeneous Effects of Mobile Internet Use among Different Regions}

The results presented in Table 10 reveal a heterogeneous effect of mobile Internet use on multidimensional poverty among regions. Table 10 shows that mobile Internet use has negative and significant impacts on multidimensional poverty in Sichuan, Henan, and Fujian, suggesting that mobile Internet use can significantly reduce multidimensional poverty for households located in these three provinces. Nevertheless, the ATTs of mobile Internet use 
Table 10 Average treatment effects on the treated (ATT) of mobile Internet use on multidimensional poverty among different regions

\begin{tabular}{llllr}
\hline \multirow{2}{*}{ Region } & \multicolumn{2}{l}{ Mean outcomes } & ATT & t-value \\
\cline { 2 - 4 } & Users & Counterfactual & & \\
\hline Sichuan & $0.724(0.035)$ & $0.821(0.041)$ & $-0.097^{*}$ & -1.799 \\
Henan & $1.032(0.027)$ & $3.038(0.190)$ & $-2.006^{* * *}$ & -10.480 \\
Fujian & $1.070(0.028)$ & $1.826(0.054)$ & $-0.756^{* * *}$ & -12.465 \\
\hline
\end{tabular}

Standard errors are in parentheses, $* p<0.1, * * * p<0.01$

on multidimensional poverty are highly varied for different provinces. For example, the ATT of mobile Internet use on multidimensional poverty in Sichuan is - 0.097 . By contrast, the ATTs in Fujian and Henan are -0.756 and -2.006, respectively. The ATTs in Fujian and Henan are much lower than that in Sichuan, indicating heterogeneous effects of mobile Internet use among different regions. This might be attributed to the varied mobile Internet usage rate in different provinces, which is presented in descriptive statistics in Table 3 . The mobile Internet usage rate in Sichuan is the lowest among the three provinces and the effect of mobile Internet on updated information extension may be relatively small, resulting in the lower effect of mobile Internet use on poverty alleviation in Sichuan.

\section{Conclusions and Discussion}

This study measured multidimensional poverty and investigated the impact of mobile Internet use on multidimensional poverty, using primary household survey data collected in rural China. Both objective and subjective dimensions were included in the multidimensional poverty measurement. Given that households decide for themselves whether or not to use mobile Internet, the ESR model was used to account for selection bias. In addition, this study also examined the heterogeneous effects of mobile Internet use on multidimensional poverty among different regions.

The results of multidimensional poverty measurement showed that $9.63 \%$ of the households are multidimensionally poor and the adjusted multidimensional poverty incidence is $5.47 \%$. These two figures are both higher than the income poverty ratio, suggesting that the poverty incidence would be underestimated if we chose income poverty measurement. This finding is in agreement with the study of Park and Nam (2020), which also showed that the multidimensional poverty rate is higher than the monetary poverty rate in South Korea. The difference between multidimensional poverty measurement and income poverty measurement might be due to the selection of poverty dimensions. Specifically, income poverty measurement only includes the dimension of income, while multidimensional poverty measurement includes both monetary and non-monetary dimensions. For example, some households may have tried to avoid monetary poverty, but they might still be deprived in non-monetary poverty dimensions (Mahadevan \& Jayasinghe, 2020).

Our estimates revealed that mobile Internet use exerts a negative and significant effect on multidimensional poverty. In particular, being a mobile Internet user results in fewer deprived dimensions than non-user counterparts. This finding broadly supports the work by $\mathrm{Ma}$ et al. (2020) who found that Internet use can significantly increase household income and expenditures. In addition, our findings also reflect the study of Hübler and Hartje (2016), which revealed that mobile ICTs such as smartphones have a positive effect on households' income in rural Southeast Asia, due to the techno-economic development 
brought by mobile ICT use. Nevertheless, the present study goes further than previous studies by investigating the effect of mobile Internet on several poverty dimensions besides income. For instance, in addition to income dimension, we also found that mobile Internet use can help rural households access public services and increase subjective wellbeing. However, unlike the findings of the present study, Galperin and Viecens (2017) concluded that the effect of Internet technologies for low-income regions remain highly uncertain. The inconsistent findings might be attributed to the discrepancy of human capital in different countries. The effective intervention of Internet technologies should be supported by various skills, relatively higher education level, and complementary investments in human capital (Galperin \& Viecens, 2017). In some less advanced countries, the amount of investment in human capital is relatively low, while other economies may attach importance to human capital investment, contributing to the different returns of Internet technologies.

With regards to the factors affecting mobile Internet use, our estimates showed that age, education, distance to market, and location variables significantly affected mobile Internet use. This finding was also reported by Mora-Rivera and García-Mora (2021), who showed that Internet access was influenced by human capital characteristics. In addition, our results echo those of Martínez-Domínguez and Mora-Rivera (2020) who found that age, educational level, and geographic location affected Internet usage. Furthermore, our estimates revealed that the impact of mobile internet use on multidimensional poverty is quite heterogeneous among different regions. The finding is supported by Leng et al. (2020), who also found that the impact of ICT adoption is heterogeneous among farmers located in different regions in China. This result may be attributed to the infrastructure gap and economic disparity among eastern, central, and western regions in China.

The findings of the present study have some policy implications. Given the importance of mobile Internet use in reducing multidimensional poverty, policy design should aim to reduce the constraints that hinder mobile Internet use in rural regions. In particular, the positive impact of education on mobile Internet use suggests that improving education level would help facilitate the willingness of households to use mobile Internet. Given that technical training is one of the important goals of adult education, governments should implement training programs that are helpful for households to better understand the applications of mobile Internet in agricultural production and daily life. The positive relationship between the distance to market and mobile Internet use indicates that governments should invest in telecommunications infrastructure for households living far from the market. For instance, governments can build more mobile telecommunications base stations and improve the coverage of mobile Internet service in remote areas. The improvement of telecommunications infrastructure will help households improve the probability of using mobile Internet, thereby promoting the development of e-commerce and fostering new drives for rural development.

Finally, some limitations need to be noted regarding the present study. First, we have identified a negative relationship between mobile Internet use and multidimensional poverty and discussed the underlying mechanisms through which mobile Internet use affects multidimensional poverty, but did not carry out the empirical analysis to test these potential mechanisms. Second, we investigated the nexus between mobile Internet use and multidimensional poverty only in China. However, many countries are quite heterogeneous in terms of economic conditions or cultural background. The generalizability of the conclusions and the extent to which they may apply in other countries still need to be tested. Third, due to the cross-sectional design, we were unable to explore the dynamic relationship between mobile Internet use and multidimensional poverty. Thus, these are important research directions to be explored in future studies. 


\section{Appendix}

\section{See Appendix Table 11}

Table 11 Validity test of instrumental variables

\begin{tabular}{lll}
\hline Variables & Mobile Internet use $(1)$ & \multicolumn{1}{c}{$\begin{array}{l}\text { The number of } \\
\text { deprived dimen- } \\
\text { sions }(2)\end{array}$} \\
\hline Age & & $-0.029(0.026)$ \\
Age squared & $0.067(0.060)$ & $0.000(0.000)$ \\
Gender & $-0.001(0.001)^{* *}$ & $-0.118(0.087)$ \\
Education & $0.156(0.141)$ & $-0.029(0.012)^{* *}$ \\
Risk aversion & $0.115(0.022)^{* * *}$ & $-0.224(0.112)^{* *}$ \\
Household size & $-0.230(0.202)$ & $-0.100(0.022)^{* * *}$ \\
Access to credit & $0.036(0.038)$ & $-0.336(0.141)^{* *}$ \\
Distance to market & $-0.090(0.204)$ & $0.041(0.009)^{* * *}$ \\
Cooperative membership & $0.035(0.019)^{*}$ & $0.005(0.085)$ \\
Henan & $-0.019(0.160)$ & $0.337(0.117)^{* * *}$ \\
Fujian & $0.989(0.202)^{* * *}$ & $0.550(0.105)^{* * *}$ \\
Home delivery service & $0.722(0.157)^{* * *}$ & $-0.130(0.088)$ \\
Friend's adoption of online shopping & $0.268(0.151)^{*}$ & $-0.047(0.083)$ \\
Constant & $0.528(0.127)^{* * *}$ & $2.455(0.743)^{* * *}$ \\
Observations & $-1.245(1.691)$ & 820
\end{tabular}

The reference region is Sichuan. Standard errors are in parentheses, $* p<0.1, * * p<0.05, * * * p<0.01$

Acknowledgements This study was supported by National Social Science Foundation of China (16CGL035), Humanities and Social Science Research Fund of the Ministry of Education of China (19YJC790063), Natural Science Foundation of Fujian (2017J05112), Scientific Innovation Fund of Fujian Agriculture and Forestry University (CXZX2019031), Special Fund of China Anti-Poverty Research Institute, Renmin University of China (CAPRI2019B08).

\section{Declarations}

Conflict of interest The authors declare that they have no conflict of interest.

\section{References}

Abeje, M. T., Tsunekawa, A., Haregeweyn, N., Ayalew, Z., Nigussie, Z., Berihun, D., et al. (2020). Multidimensional poverty and inequality: Insights from the Upper Blue Nile Basin Ethiopia. Social Indicators Research, 149(2), 585-611.

Alalwan, A. A., Baabdullah, A. M., Rana, N. P., Tamilmani, K., \& Dwivedi, Y. K. (2018). Examining adoption of mobile internet in Saudi Arabia: Extending TAM with perceived enjoyment, innovativeness and trust. Technology in Society, 55, 100-110.

Alkire, S., \& Foster, J. (2011). Counting and multidimensional poverty measurement. Journal of Public Economics, 95(7-8), 476-487.

Alkire, S., \& Seth, S. (2015). Multidimensional poverty reduction in India between 1999 and 2006: Where and How? World Development, 72, 93-108. 
Atasoy, H. (2013). The effects of broadband Internet expansion on labor market outcomes. Industrial and Labor Relations Review, 66(2), 315-345.

Bekun, F. V., \& Akadiri, S. S. (2019). Poverty and agriculture in Southern Africa revisited: A panel causality perspective. SAGE Open, 9(1), 1-10.

Beuermann, D. W., McKelvey, C., \& Vakis, R. (2012). Mobile phones and economic development in Rural Peru. Journal of Development Studies, 48(11), 1617-1628.

Chu, Z., Wang, Z., Xiao, J. J., \& Zhang, W. (2017). Financial literacy, portfolio choice and financial wellbeing. Social Indicators Research, 132(2), 799-820.

Colombo, M. G., Croce, A., \& Grilli, L. (2013). ICT services and small businesses' productivity gains: An analysis of the adoption of broadband Internet technology. Information Economics and Policy, 25(3), 171-189.

Del Gaudio, B. L., Porzio, C., Sampagnaro, G., \& Verdoliva, V. (2020). How do mobile, internet and ICT diffusion affect the banking industry? An empirical analysis. European Management Journal, https:// doi.org/10.1016/j.emj.2020.07.003

Deshpande, A., Desrochers, A., Ksoll, C., \& Shonchoy, A. S. (2017). The impact of a computer-based adult literacy program on literacy and numeracy: Evidence from India. World Development, 96, 451-473.

Fernandes, A. M., Mattoo, A., Nguyen, H., \& Schiffbauer, M. (2019). The internet and Chinese exports in the pre-ali baba era. Journal of Development Economics, 138, 57-76.

$\mathrm{Fu}, \mathrm{X}$., \& Akter, S. (2016). The impact of mobile phone technology on agricultural extension services delivery: Evidence from India. Journal of Development Studies, 52(11), 1561-1576.

Galperin, H., \& Fernanda Viecens, M. (2017). Connected for development? Theory and evidence about the impact of Internet technologies on poverty alleviation. Development Policy Review, 35(3), 315-336.

Hübler, M., \& Hartje, R. (2016). Are smartphones smart for economic development ? Economics Letters, $141,130-133$.

Khonje, M., Manda, J., Alene, A. D., \& Kassie, M. (2015). Analysis of adoption and impacts of improved maize varieties in Eastern Zambia. World Development, 66, 695-706.

Langmia, K. (2005). The role of ICT in the economic development of Africa: The case of South Africa. International Journal of Educationand Development Using Information and Communication Technology, 2(4), 144-156.

Lei, Y., Guo, Y., Zhang, Y., \& Cheung, W. (2021). Information technology and service diversification: A cross-level study in different innovation environments. Information \& Management. https://doi.org/10. 1016/j.im.2021.103432

Leng, C., Ma, W., Tang, J., \& Zhu, Z. (2020). ICT adoption and income diversification among rural households in China. Applied Economics. https://doi.org/10.1080/00036846.2020.1715338

Lio, M., \& Liu, M. C. (2006). ICT and agricultural productivity: Evidence from cross-country data. Agricultural Economics, 34(3), 221-228.

Lu, H., Nie, P., \& Qian, L. (2020). Do quarantine experiences and attitudes towards COVID-19 affect the distribution of mental health in China? A quantile regression analysis. Applied Research in Quality of Life, https://doi.org/10.1007/s11482-020-09851-0

Ma, W., Renwick, A., Nie, P., Tang, J., \& Cai, R. (2018). Off-farm work, smartphone use and household income: Evidence from rural China. China Economic Review, 52, 80-94.

Ma, W., Nie, P., Zhang, P., \& Renwick, A. (2020). Impact of Internet use on economic well-being of rural households: Evidence from China. Review of Development Economics. https://doi.org/10.1111/rode. 12645

Mahadevan, R., \& Jayasinghe, M. (2020). Examining multidimensional poverty in Sri Lanka: Transitioning through post war conflict. Social Indicators Research, 149(1), 15-39.

Martínez-Domínguez, M., \& Mora-Rivera, J. (2020). Internet adoption and usage patterns in rural Mexico. Technology in Society, 60, 101226.

Masanjala, W. H. (2006). Cash crop liberalization and poverty alleviation in Africa: Evidence from Malawi. Agricultural Economics, 35(2), 231-240.

Mbuyisa, B., \& Leonard, A. (2017). The role of ICT use in SMEs towards poverty reduction: A systematic literature review. Journal of International Development, 29(2), 159-197.

Mora-Rivera, J., \& García-Mora, F. (2021). Internet access and poverty reduction: Evidence from rural and urban Mexico. Telecommunications Policy, 45(2), 102076.

Munyegera, G. K., \& Matsumoto, T. (2016). Mobile money, remittances, and household welfare: Panel evidence from rural Uganda. World Development, 79, 127-137.

Munyegera, G. K., \& Matsumoto, T. (2018). ICT for financial access: Mobile money and the financial behavior of rural households in Uganda. Review of Development Economics, 22(1), 45-66.

Mushtaq, R., \& Bruneau, C. (2019). Microfinance, financial inclusion and ICT: Implications for poverty and inequality. Technology in Society, 59, 101154. 
Ngoma, H. (2018). Does minimum tillage improve the livelihood outcomes of smallholder farmers in Zambia? Food Security, 10(2), 381-396.

Niebel, T. (2018). ICT and economic growth-Comparing developing, emerging and developed countries. World Development, 104, 197-211.

Nowak, D., \& Scheicher, C. (2017). Considering the extremely poor: Multidimensional poverty measurement for Germany. Social Indicators Research, 133(1), 139-162.

Ogutu, S. O., \& Qaim, M. (2019). Commercialization of the small farm sector and multidimensional poverty. World Development, 114, 281-293.

Park, A., \& Wang, S. (2010). Community-based development and poverty alleviation: An evaluation of China's poor village investment program. Journal of Public Economics, 94(9-10), 790-799.

Park, E. Y., \& Nam, S. J. (2020). Multidimensional poverty status of householders with disabilities in South Korea. International Journal of Social Welfare, 29(1), 41-50.

Paunov, C., \& Rollo, V. (2016). Has the Internet fostered inclusive innovation in the developing world? World Development, 78, 587-609.

Pomati, M., \& Nandy, S. (2020). Measuring multidimensional poverty according to national definitions: Operationalising target 1.2 of the sustainable development goals. Social Indicators Research, 148(1), $105-126$.

Qiang, C.Z.-W., Rossotto, C. M., \& Kimura, K. (2009). (2009) Economic impacts of broadband. Information and communications for development. Extending Reach and Increasing Impact, 3, 35-50.

Salemink, K., Strijker, D., \& Bosworth, G. (2017). Rural development in the digital age: A systematic literature review on unequal ICT availability, adoption, and use in rural areas. Journal of Rural Studies, $54,360-371$.

Santos, M. E., \& Villatoro, P. (2018). A multidimensional poverty index for Latin America. Review of Income and Wealth, 64(1), 52-82.

Sargan, J. D. (1958). The estimation of economic relationships using instrumental variables. Econometrica, 26(3), 393-415.

Shiferaw, B., Kassie, M., Jaleta, M., \& Yirga, C. (2014). Adoption of improved wheat varieties and impacts on household food security in Ethiopia. Food Policy, 44, 272-284.

Strotmann, H., \& Volkert, J. (2018). Multidimensional poverty index and happiness. Journal of Happiness Studies, 19, 167-189.

Sujarwoto, S., \& Tampubolon, G. (2016). Spatial inequality and the Internet divide in Indonesia 2010-2012. Telecommunications Policy, 40(7), 602-616.

Tang, W., \& Zhu, J. (2020). Informality and rural industry: Rethinking the impacts of E-Commerce on rural development in China. Journal of Rural Studies, 75, 20-29.

van Deursen, A. J. A. M., \& van Dijk, J. A. G. M. (2019). The first-level digital divide shifts from inequalities in physical access to inequalities in material access. New Media and Society, 21(2), 354-375.

Viollaz, M. (2019). Information and communication technology adoption in micro and small firms: Can internet access improve labour productivity? Development Policy Review, 37(5), 692-715.

Xie, P., Sun, F., Wang, L., \& Liu, P. (2019). A review on China's energy storage industry under the "Internet Plus" initiative. International Journal of Energy Research, 43(2), 717-741.

Zheng, X., \& Lu, H. (2021). Does ICT change household decision-making power of the left-behind women? A case from China. Technological Forecasting and Social Change, 166. https://doi.org/10.1016/j.techf ore.2021.120604

Publisher's Note Springer Nature remains neutral with regard to jurisdictional claims in published maps and institutional affiliations. 